\title{
The relation between standardized test scores and NCLEX-RN failure
}

\author{
Lindsay Sandridge Domiano, Danielle Charrier \\ Nursing Department, Southeastern Louisiana University, United States
}

Received: August 6, 2019

Accepted: October 8, 2019

Online Published: October 17, 2019

DOI: $10.5430 /$ jnep.v10n1p101

URL: https://doi.org/10.5430/jnep.v10n1p101

\begin{abstract}
First time pass rates on the National Council Licensure Examination - Registered Nurses (NCLEX-RN) are the desired outcome of Schools of Nursing across the United States. The purpose of this study was to determine if there was a relation between standardized testing scores and NCLEX-RN failure among students in a baccalaureate nursing program. This study utilized a retrospective correlational design to identify relations between the dependent variables NCLEX-RN failure and the independent variables. The 16 Independent Variables were: Fundamentals of Nursing Practice and Repeat, Adult Health Nursing and Repeat, Mental Health Nursing and Repeat, Pediatric Nursing and repeat, Obstetrical Nursing and Repeat, Community Health Nursing and Repeat, RN Exit Exam and Repeat, and Pharmacology and Pharmacology Repeat. The statistical tests utilized for data analysis were: logistic regression, multiple logistic regression model, and Pearson's $\chi^{2}$ cross-tabulations. Significant findings identified students "at risk" for NCLEX-RN failure. Faculty intervention early on and throughout the students' nursing program will help improve student outcomes, NCLEX-RN success, and ultimately helping to alleviate the nursing shortage.
\end{abstract}

Key Words: Standardized testing, Nursing curriculum, Nursing student, NCLEX-RN success

\section{INTRODUCTION}

First time pass rates on the National Council Licensure Examination - Registered Nurses (NCLEX-RN) are the desired outcome of Schools of Nursing across the United States. Schools of Nursing are expected to maintain high percentages of first time pass rates in order to meet accreditation standards. It is the responsibility of the faculty and schools of nursing to adequately prepare students to perform successfully on the NCLEX-RN. Programs must meet licensure requirements that are identified in standard IV-C of the Commission on Collegiate Nursing Education's (CCNE) Standards for Accreditation of Baccalaureate and Graduate Programs of Nursing (2018). ${ }^{[1]}$ Schools of nursing need to produce safe and competent nursing graduates that pass the
NCLEX-RN in order to help alleviate the national nursing shortage. According to the Bureau of Labor Statistics' Occupational Employment Projections to 2024 (2015), ${ }^{[2]}$ the demand for registered nurses will increase $16 \%$ by the year 2024, totaling 3.2 million nurses.

Schools of nursing utilize numerous different teaching strategies and methodologies in order to enhance student learning and prepare nursing graduates to be successful registered nurses. Standardized testing throughout the curriculum has been shown to improve student success on the NCLEXRN. ${ }^{[3-5]}$ The study conducted by Brussow and Dunham examined the relation between nine content mastery (CMS) assessments and the comprehensive predictive (CP) test. It also looked at the relation between CP scores and the proba-

\footnotetext{
* Correspondence: Lindsay Sandridge Domiano; Email: Lindsay.Domiano@ selu.edu; Address: Nursing Department, Southeastern Louisiana University, United States.
} 
bility of passing NCLEX-RN. Results revealed there were correlations between scores on all CMS assessments and the $\mathrm{CP}$ assessment. Students' probability of passing the NCLEX RN was categorized by their CP scores. Ninety-one percent of students that completed all 9 CMS assessments successfully were considered "highly likely to pass" the NCLEX-RN. As the number of successful CMS attempts decreased, so did the percentage of students that were "highly likely to pass". The three assessments that were most predictive of performance on the $\mathrm{CP}$ assessment were: Adult Med-Surg, Leadership and Nursing Care of Children. The least predictive, while still significant, was Fundamentals. ${ }^{[3]}$ Homard $(2013)^{[4]}$ conducted a study to compare exit exam scores and NCLEX-RN pass rates among students who participated in standardized testing packages at varying levels in their curriculum. Some students had no standardized testing package, some students had standardized testing for two semesters and the final group has standardized testing for 4 semesters. Those students who were most likely to be successful on their exit exam and NCLEX-RN participated in four semesters of a standardized testing package (Homard, 2013). Langford and Young (2013), studied the relation between the Hesi Exit Exam (E2) and NCLEX-RN success. Results revealed that success on the NCLEX-RN was highly predicted by testing and repeat testing on the E2, specifically $94.93 \%-98.32 \% .{ }^{[5]}$

There is controversial literature regarding the utilization of standardized tests as high-stakes testing in nursing programs. ${ }^{[6-9]}$ According to these studies, positive consequences of standardized testing such as feedback, remediation, guidance, and curriculum modifications are all keys to increasing student success. Harlan conducted a single group pretest/post-test quasi-experimental design which revealed an increase in standardized testing exam scores with the use of remediation between each attempt. ${ }^{[6]}$ A qualitative study by Stonecypher et al. (2015) ${ }^{[9]}$ supported the use of standardized testing in order to give focused feedback and remediation opportunities. Programs varied in the type and amount remediation assigned.

The purpose of this study was to determine if there was a relation between standardized testing scores and NCLEX-RN failure among students in a baccalaureate nursing program. Discovering relations between standardized test scores and the NLCEX-RN will allow faculty to modify curriculum, remediation, and progression policies in order to enhance the overall success of nursing graduates on the NCLEX-RN.

\section{METHOD}

This study was conducted in one baccalaureate prepared school of nursing located in the southeastern region of the United States. This study utilized a retrospective correla- tional design to identify relations between the dependent variables NCLEX-RN failure and the independent variables. The 16 Independent Variables were: Fundamentals of Nursing Practice and Repeat, Adult Health Nursing and Repeat, Mental Health Nursing and Repeat, Pediatric Nursing and repeat, Obstetrical Nursing and Repeat, Community Health Nursing and Repeat, RN Exit Exam and Repeat, and Pharmacology and Pharmacology Repeat. The target population was defined as students enrolled in a baccalaureate program that utilizes standardized assessments throughout the curriculum. All students that were enrolled in the nursing program between the years of 2013 and 2017 were included in the study. Students were excluded if they failed to complete the program or did not sit for the NCLEX-RN examination. The sample size consisted of 554 students. The results from the standardized test scores and NCLEX-RN were manually inputted into an Excel spreadsheet. The data was then analyzed utilizing Statistical Package for the Social Sciences (SPSS). Prior to implementation the researchers gained Institutional Review Board approval from their university.

The research aim for this study was to determine what standardized assessments or collection of assessments best predicted failure on the NCLEX. For the first group, a logistic regression was conducted including all of the non-retake assessments in the model to determine if failure on these exams predicted failure on the NCLEX. Due to all variables being non-retake data, this preserved the largest amount of sample. As an added step, a backward stepwise (conditional) multiple logistic regression model was conducted that employed the use of an algorithm to find the best combination of predictors for the outcome. The algorithm stopped at the fourth step. For the analyses with the standardized assessment retakes with the NCLEX initial tests, sample size was reduced to the extent that logistic regression estimates were not feasible. Accordingly, Pearson's $\chi^{2}$ cross-tabulations for each retake assessment by the NCLEX were conducted. For the analyses with the standardized assessments non-retakes with the NCLEX retakes, sample size was reduced to the extent that logistic regression estimates were not feasible. Pearson's $\chi^{2}$ cross-tabulations for each retake assessment by the NCLEX retake were conducted.

\section{RESULTS}

Frequencies and percentages for categorical study variables are shown in Table 1.

\subsection{Primary analysis}

The results of the logistic regression including all of the non-retake assessments are provided in Table 2 . The overall model was statistically significant, $\chi^{2}(\mathrm{df})=88.96, p<.001$,

ISSN 1925-4040 E-ISSN 1925-4059 
Cox and Snell's $R^{2}=.148$, Nagelkerke $R^{2}=.395$. Failure on the Adult Health Nursing (OR $=3.13, p=.036)$, Mental Health Nursing (OR $=5.18, p<.001)$, Pediatric Nursing $(\mathrm{OR}=3.21, p=.005)$, and $\mathrm{RN}$ Exit $(\mathrm{OR}=2.85, p=.015)$ assessments predicted failure on the NCLEX. These findings suggest that for the strongest predictor, students who fail initially on the Mental Health Nursing assessment are 5.18 time more likely to fail their first try on the NCLEX. Fundamentals of Nursing, Obstetrical Nursing, Pharmacology, and Community Health Nursing were not significant predictors of NCLEX failure in this model.

The results of the multiple logistic regression model are shown in Table 3. The overall model was statistically significant, $\chi^{2}(\mathrm{df})=87.93, p<.001$, Cox and Snell's $R^{2}=$ .147 , Nagelkerke $R^{2}=.391$. Failure on the Fundamentals of Nursing (OR $=2.34, p=.043)$, Adult Health Nursing (OR $=3.34, p=.025)$, Mental Health Nursing $(\mathrm{OR}=5.13, p<$ $.001)$, Pediatric Nursing (OR $=3.27, p=.004)$, and RN Exit $(\mathrm{OR}=3.09, p=.008)$ assessments predicted failure on the NCLEX. These findings indicate that the strongest predictor, students who fail initially on the Mental Health Nursing, are 5.13 time more likely to fail the NCLEX.

The results of the Pearson's $\chi^{2}$ cross-tabulations for each retake assessment by the NCLEX are provided in Table 4 . There were four significant findings. Fundamentals of Nursing retake by NCLEX had overall significant model fit, $\chi^{2}$ (1) $=4.81, p=.028$, Cramer's $V=.181$. Of those participants who failed the Fundamentals of Nursing retake $34.8 \%$ failed the NCLEX, compared to $15.4 \%$ who passed. In other words, participants who fail the Fundamentals of Nursing retake are more than twice as likely to fail the NCLEX compared to those who pass the NCLEX. The Adult Health Nursing retake by NCLEX had overall significant model fit, $\chi^{2}(1)=10.43$, $\mathrm{p}=.001$, Cramer's $\mathrm{V}=.222$. Of those participants who failed the Adult Health Nursing retake $63.3 \%$ failed the NCLEX, compared to $32.6 \%$ who passed. The Mental Health Nursing retake by NCLEX had overall significant model fit, $\chi^{2}(1)$ $=13.71, p<.001$, Cramer's V $=.299$. Of those participants who failed the Mental Health Nursing retake $60.7 \%$ failed the NCLEX, compared to $24.8 \%$ who passed. The RN Exit retake by NCLEX had overall significant model fit, $\chi^{2}(1)$ $=12.70, p<.001$, Cramer's V $=.169$. Of those participants who failed the RN Exit retake $73.9 \%$ failed the NCLEX, compared to $32.5 \%$ who passed. The other retake assessments were not statistically significant in these analyses.

Regarding Pearson's $\chi^{2}$ cross-tabulations for each retake assessment by the NCLEX retake, there were two significant findings. These results are located in Table 5. Obstetrical Nursing assessment by NCLEX retake had overall significant model fit, $\chi^{2}(1)=5.83, p=.033$, Cramer's $\mathrm{V}=.408$. Of those participants who failed the Obstetrical Nursing, $57.1 \%$ failed the NCLEX retake, compared to $14.3 \%$ who passed.

Table 1. Frequencies and Percentages of Study Variables

\begin{tabular}{|c|c|c|}
\hline Variables & $n$ & $\%$ \\
\hline \multicolumn{3}{|c|}{ Fundamentals of Nursing Practice } \\
\hline Pass & 408 & 73.6 \\
\hline Fail & 146 & 26.4 \\
\hline \multicolumn{3}{|c|}{ Adult Health Nursing } \\
\hline Pass & 343 & 61.9 \\
\hline Fail & 211 & 38.1 \\
\hline \multicolumn{3}{|c|}{ Mental Health Nursing } \\
\hline Pass & 401 & 72.4 \\
\hline Fail & 153 & 27.6 \\
\hline \multicolumn{3}{|c|}{ Pediatric Nursing } \\
\hline Pass & 458 & 82.7 \\
\hline Fail & 96 & 17.3 \\
\hline \multicolumn{3}{|c|}{ Obstetrical Nursing } \\
\hline Pass & 518 & 93.5 \\
\hline Fail & 36 & 6.5 \\
\hline \multicolumn{3}{|c|}{ Pharmacology } \\
\hline Pass & 366 & 66.1 \\
\hline Fail & 188 & 33.9 \\
\hline \multicolumn{3}{|c|}{ Community Health Nursing } \\
\hline Pass & 419 & 75.6 \\
\hline Fail & 135 & 24.4 \\
\hline \multicolumn{3}{|c|}{ RN Exit Exam } \\
\hline Pass & 448 & 80.9 \\
\hline Fail & 106 & 19.1 \\
\hline \multicolumn{3}{|c|}{ Fundamentals of Nursing Retake } \\
\hline Pass & 119 & 21.5 \\
\hline Fail & 27 & 4.9 \\
\hline \multicolumn{3}{|c|}{ Adult Health Nursing Retake } \\
\hline Pass & 133 & 24.0 \\
\hline Fail & 78 & 14.1 \\
\hline \multicolumn{3}{|c|}{ Mental Health Nursing Retake } \\
\hline Pass & 105 & 19.0 \\
\hline Fail & 48 & 8.7 \\
\hline \multicolumn{3}{|c|}{ Pediatric Nursing Retake } \\
\hline Pass & 63 & 11.4 \\
\hline Fail & 33 & 6.0 \\
\hline \multicolumn{3}{|c|}{ Obstetrical Nursing Retake } \\
\hline Pass & 32 & 5.8 \\
\hline Fail & 4 & .7 \\
\hline \multicolumn{3}{|c|}{ Pharmacology Retake } \\
\hline Pass & 106 & 19.1 \\
\hline Fail & 82 & 14.8 \\
\hline \multicolumn{3}{|c|}{ Community Health Nursing Retake } \\
\hline Pass & 74 & 13.4 \\
\hline Fail & 61 & 11.0 \\
\hline \multicolumn{3}{|c|}{ RN Exit Exam Retake } \\
\hline Pass & 62 & 11.2 \\
\hline Fail & 44 & 7.9 \\
\hline \multicolumn{3}{|l|}{ NCLEX } \\
\hline Pass & 519 & 93.7 \\
\hline Fail & 35 & 6.3 \\
\hline \multicolumn{3}{|c|}{ NCLEX retake } \\
\hline Pass & 546 & 98.6 \\
\hline Fail & 7 & 1.3 \\
\hline
\end{tabular}


In other words, participants who fail the Obstetrical Nurs- $100.0 \%$ failed the NCLEX retake, compared to the 53.6\% ing are almost four times as likely to fail the NCLEX retake who passed. All other standardized assessment cross tabulacompared to those who pass the NCLEX retake. The Pharma- tions of the NCLEX retake were not statistically significant cology assessment by NCLEX retake had overall significant in these analyses. Due to small observed counts $(<5$ frequenmodel fit, $\chi^{2}(1)=5.17, p=.031$, Cramer's $\mathrm{V}=.384$. Of $\quad$ cies per cell), Fisher's Exact test was conducted to determine those participants who failed the Pharmacology Assessment, statistical significance (see Table 5).

Table 2. Logistic Regression Analysis Using Standardized Assessments and RN Failures to Predict NCLEX Failure

\begin{tabular}{llllll}
\hline Predictors & $\boldsymbol{B}$ & $\boldsymbol{S E}$ & Wald & $\boldsymbol{p}$ & \multicolumn{1}{c}{$\boldsymbol{O R}$} \\
\hline Fundamentals of Nursing failure $^{*}$ & .805 & .43 & 3.43 & .064 & 2.236 \\
Adult Health Nursing failure $^{*}$ & 1.141 & .55 & 4.38 & .036 & 3.131 \\
Mental Health failure $^{*}$ & 1.645 & .47 & 12.32 & .000 & 5.182 \\
Pediatric Nursing failure $^{*}$ & 1.165 & .41 & 7.97 & .005 & 3.207 \\
Obstetrical Nursing failure $^{*}$ & .257 & .54 & .23 & .635 & 1.293 \\
Pharmacology failure $^{*}$ & .356 & .43 & .70 & .404 & 1.427 \\
Community Health Nursing failure $^{*}$ & -.053 & .43 & .02 & .902 & .948 \\
RN Exit Exam failure $^{*}$ & 1.048 & .43 & 5.87 & .015 & 2.853 \\
Constant & -5.664 & .63 & 81.70 & .000 & .003 \\
\hline
\end{tabular}

Note. $N=554, \chi^{2}(\mathrm{df})=88.96, p<.001$, Cox and Snell's $R^{2}=.148$, Nagelkerke $R^{2}=.395$. ${ }^{*}$ Compared to passing the test.

Table 3. Backward Stepwise Conditional Logistic Regression Analysis Using Standardized Assessments and RN Failures to Predict NCLEX Failure

\begin{tabular}{llllll}
\hline Predictors & $\boldsymbol{B}$ & $\boldsymbol{S E}$ & Wald & $\boldsymbol{p}$ & OR \\
\hline Fundamentals of Nursing failure $^{*}$ & .850 & .42 & 4.08 & .043 & 2.340 \\
Adult Health Nursing failure $^{*}$ & 1.207 & .54 & 5.02 & .025 & 3.342 \\
Mental Health Nursing failure $^{*}$ & 1.635 & .47 & 12.25 & .000 & 5.130 \\
Pediatric Nursing failure $^{*}$ & 1.184 & .41 & 8.34 & .004 & .008 \\
RN Exit Exam failure $^{*}$ & 1.127 & .43 & 6.98 & .000 & 3.086 \\
Constant & -5.562 & .60 & 87.45 & .000 & .004 \\
\hline
\end{tabular}

Note. $N=554, \chi^{2}(\mathrm{df})=87.93, p<.001$, Cox and Snell's $R^{2}=.147$, Nagelkerke $R^{2}=.391 .{ }^{*}$ Compared to passing the test.

Table 4. Frequencies and Percentages of Assessment Retakes by NCLEX Initial Test

\begin{tabular}{|c|c|c|c|c|c|c|c|c|c|}
\hline \multirow{3}{*}{ Variable by NCLEX } & \multicolumn{6}{|c|}{ NCLEX } & \multirow{3}{*}{$\chi^{2}$} & \multirow{3}{*}{$p$} & \multirow{3}{*}{$\boldsymbol{V}$} \\
\hline & \multicolumn{3}{|l|}{ Pass } & \multicolumn{3}{|c|}{ Fail } & & & \\
\hline & $n$ & $\%$ & & $n$ & $\%$ & & & & \\
\hline \multicolumn{4}{|c|}{ Fundamentals of Nursing Practice retake } & & & & 4.81 & .028 & .181 \\
\hline Pass & 104 & 84.6 & a & 15 & 65.2 & $\mathrm{~b}$ & & & \\
\hline Fail & 19 & 15.4 & a & 8 & 34.8 & $\mathrm{~b}$ & & & \\
\hline Adult Health Nursing retake & & & & & & & 10.43 & .001 & .222 \\
\hline Pass & 122 & 67.4 & a & 11 & 36.7 & $\mathrm{~b}$ & & & \\
\hline Fail & 59 & 32.6 & a & 19 & 63.3 & $\mathrm{~b}$ & & & \\
\hline Mental Health Nursing retake & & & & & & & 13.71 & $<.001$ & .299 \\
\hline Pass & 94 & 75.2 & a & 11 & 39.3 & $\mathrm{~b}$ & & & \\
\hline Fail & 31 & 24.8 & $\mathrm{a}$ & 17 & 60.7 & $\mathrm{~b}$ & & & \\
\hline RN Exit Exam retake & & & & & & & 12.70 & $<.001$ & .169 \\
\hline Pass & 56 & 67.5 & $\mathrm{a}$ & 6 & 26.1 & $\mathrm{~b}$ & & & \\
\hline Fail & 27 & 32.5 & $\mathrm{a}$ & 17 & 73.9 & b & & & \\
\hline
\end{tabular}

Note. For each row category, pairs of column proportions with different superscripts (a and b) differed significantly, $p<.05$. 
Table 5. Frequencies and Percentages of Standardized Assessments Initial Test by NCLEX Retake

\begin{tabular}{|c|c|c|c|c|c|c|c|c|c|}
\hline \multirow{3}{*}{ Variable by NCLEX retake } & \multicolumn{6}{|c|}{ NCLEX retake } & \multirow{3}{*}{$\chi^{2}$} & \multirow{3}{*}{$p$} & \multirow{3}{*}{$\boldsymbol{V}$} \\
\hline & \multicolumn{3}{|c|}{ Pass } & \multicolumn{3}{|c|}{ Fail } & & & \\
\hline & $n$ & $\%$ & & $n$ & $\%$ & & & & \\
\hline Obstetrical Nursing $^{\psi}$ & & & & & & & 5.83 & .033 & .408 \\
\hline Pass & 24 & 85.7 & a & 3 & 42.9 & $\mathrm{~b}$ & & & \\
\hline Fail & 4 & 14.3 & a & 4 & 57.1 & $\mathrm{~b}$ & & & \\
\hline Pharmacology ${ }^{\psi}$ & & & & & & & 5.17 & .031 & .384 \\
\hline Pass & 13 & 46.4 & a & 0 & .0 & $\mathrm{~b}$ & & & \\
\hline Fail & 15 & 53.6 & a & 7 & 100.0 & $\mathrm{~b}$ & & & \\
\hline
\end{tabular}

Note. For each row category, pairs of column proportions with different superscripts (a and b) differed significantly, $p<.05$. $\psi$ Indicates that due to cells with 0 frequency counts and/or below 5 frequency counts, Fisher's Exact test $p$-values are reported.

For the final group of standardized testing retakes with NCLEX retakes, none of the analyses were statistically significant at $p<.05$ and were excluded from reporting.

\section{DiscuSSION AND CONCLUSION}

Significant findings identified students "at risk" for NCLEX$\mathrm{RN}$ failure. Identifying these students early will enable faculty members to enhance needed curriculum content and develop remediation programs. Students will benefit from faculty proactively managing them throughout their coursework rather than waiting until NCLEX-RN is imminent. Remediation modules can be developed utilizing course content as well as the curriculum testing resources. These interventions will help to provide positive student outcomes.

The study results revealed failure on the Adult Health Nursing, Mental Health Nursing, Pediatric Nursing, and RN Exit assessments predicted failure on the NCLEX-RN. These results are similar with the findings of Brussow \& Dunham $(2018)^{[3]}$ who found three assessments to be significant for success on the CP assessment and ultimately the NCLEX-RN. The results also reinforce the findings by Homard (2013) ${ }^{[4]}$ and Langford \& Young (2013) ${ }^{[5]}$ that student success on the NCLEX-RN is heightened by standardized testing throughout the curriculum. Significant findings for standardized assessments may not be uniform for every school of nursing program. It is the responsibility of the faculty to determine which standardized assessments are predictive of student performance on the NCLEX-RN for their individual nursing programs.
This study was conducted in one school of nursing with a baccalaureate program. This is a limitation and more studies are needed to examine the relation between standardized testing assessments and NCLEX-RN performance in schools with all levels of nursing programs. Results may not be generalized to LPN or ADN students and programs. Another limitation to consider is the NCLEX-RN passage rate of the program studied. The NCLEX-RN passage rate is significantly higher than the state and national passage rates. Further research is needed to identify at risk students in programs with historically lower NCLEX-RN passage rates.

It is imperative that nursing programs implement procedures to identify at risk students in their programs and incorporate remediation polices throughout the curriculum. A thorough evaluation of the schools' standardized testing package, and testing/remediation policies must be conducted to identity characteristics of at risk students. Testing and remediation policies need to be developed based on the individual student and program needs. This is also supported by previous research studies by Harlan (2017); ${ }^{[6]}$ Hunsicker \& Chitwood (2018); ${ }^{[7]}$ Randolph (2017), ${ }^{[8]}$ Stonecypher et al. (2015). ${ }^{[9]}$

Finally, an increase in NCLEX-RN passage rates will help schools of nursing meet their program objectives and accreditation requirements. An increase in NCLEX-RN passage rates for schools of nursing will also produce safe and competent nurses for the workforce-helping to alleviate the projected nursing shortage.

\section{CONFlicts OF InTEREST Disclosure}

The authors declare that there is no conflict of interest.

\section{REFERENCES}

[1] Commission on Collegiate Nursing Education (2018). Standards for accreditation of baccalaureate and graduate programs. Available from: https ://www . aacnnursing.org/Portals/42/CCNE/PD

Published by Sciedu Press
F/Standards-Final-2018.pdf

[2] United States Department of Labor. Occupational employment projections to 2024. 2015. Available from: https://www.bls.gov/opub/mlr/2015/article/occu 
pational-employment-projections-to-2024.htm

[3] Brussow J, Dunham M. Students' midprogram content area performance as a predictor of end-of-program NCLEX readiness. Nurse Educator. 2018; 43(5): 238-241. PMid:29271817 https ://doi .or $\mathrm{g} / 10.1097 / \mathrm{NNE} .0000000000000499$

[4] Homard C. Impact of a standardized test package on exit examination scores and NCLEX-RN outcomes. Journal of Nursing Education. 2013; 52(3): 175-178. PMid:23413805 https://doi.org/10.3 928/01484834-20130219-01

[5] Langford R, Young A. Predicting NCLEX-RN success with the HESI exit exam: Eighth validity Study. Journal of Professional Nursing. 2013; 29(2S): S5-S9. PMid:23566508 https ://doi .org/10.101 $6 / j . p r o f n u r s .2012 .06 .007$
[6] Harlan A. How does standardized testing and a structured remediation plan affect ATI second attempt assessment scores and student self-efficacy? Kentucky Nurse. 2017; 13.

[7] Hunsicker J, Chitwood T. High-stakes testing in nursing education: A review of literature. Nurse Educator. 2018; 43(4): 183-186. PMid:29135716 https : //doi.org/10.1097/NNE. 0000000000 000475

[8] Randolph P. Standardized testing practices: Effect on graduation and NCLEX pass rates. The Journal of Professional Nursing. 2017; 33(3): 224-228. PMid:28577815 https ://doi.org/10.1016/j. profnurs.2016.09.002

[9] Stonecypher K, Young A, Langford R, et al. Faculty experiences developing and implementing policies for exit exam testing. Nurse Educator. 2015; 40(4): 189-193. PMid:25783812 https ://doi.or g/10.1097/NNE. 0000000000000152 